\title{
Association between Influenza Vaccination and Positive SARS-CoV-2 IgG and IgM Tests in the General Population of Katowice Region, Poland
}

\author{
Małgorzata Kowalska ${ }^{1}$ (D), Ewa Niewiadomska ${ }^{2}$, Kamil Barański ${ }^{1} *\left(\mathbb{D}\right.$, Angelina Kaleta-Pilarska ${ }^{1}$ (D), \\ Grzegorz Brożek $^{1}\left(\mathbb{D}\right.$ and Jan Eugeniusz Zejda ${ }^{1}$
}

1 Department of Epidemiology, School of Medical Sciences in Katowice, Medical University of Silesia in Katowice, 40-752 Katowice, Poland; mkowalska@sum.edu.pl (M.K.); akaleta@sum.edu.pl (A.K.-P.); gbrozek@sum.edu.pl (G.B.); jzejda@sum.edu.pl (J.E.Z.)

2 Department of Epidemiology and Biostatistics, School of Public Health in Bytom, Medical University of Silesia in Katowice, 41-902 Katowice, Poland; eniewiadomska@sum.edu.pl

* Correspondence: kbaranski@sum.edu.pl; Tel.: +48-208-85-36

\section{check for}

updates

Citation: Kowalska, M.;

Niewiadomska, E.; Barański, K.;

Kaleta-Pilarska, A.; Brożek, G.; Zejda,

J.E. Association between Influenza

Vaccination and Positive

SARS-CoV-2 IgG and IgM Tests in the General Population of Katowice

Region, Poland. Vaccines 2021, 9, 415.

https://doi.org/10.3390/

vaccines 9050415

Academic Editor: Betsy C. Herold

Received: 4 March 2021

Accepted: 15 April 2021

Published: 21 April 2021

Publisher's Note: MDPI stays neutral with regard to jurisdictional claims in published maps and institutional affiliations.

Copyright: (c) 2021 by the authors. Licensee MDPI, Basel, Switzerland. This article is an open access article distributed under the terms and conditions of the Creative Commons Attribution (CC BY) license (https:// creativecommons.org/licenses/by/ $4.0 /)$.

\begin{abstract}
The explanation of the potential interaction between the influenza vaccine and SARS-CoV2 infection is urgently needed in the public health. The objective of the study is to compare the occurrence of positive SARS-CoV-2 IgG and IgM tests in subjects with and without recent (last year) seasonal influenza vaccinations. In a cross-sectional study located in three large towns of Silesian Voivodeship (Poland), we studied 5479 subjects in which 1253 (22.9\%) had a positive anti-SARS-CoV2 IgG test and $400(7.3 \%)$ had a positive anti-SARS-CoV-2 IgM test. Seasonal influenza vaccination remains an independent factor protecting against positive IgG tests $(\mathrm{OR}=0.68 ; 0.55-0.83)$. The effect is not apparent with $\operatorname{IgM}$ antibodies. The obtained results confirmed that the serological status of SARS-CoV-2 infection depends on vaccination against seasonal influenza.
\end{abstract}

Keywords: influenza vaccination; seropositivity of COVID-19; cross-sectional study

\section{Introduction}

Influenza and COVID-19 are respiratory viral illnesses that may present with similar symptoms, and coinfections can result in more serious complications with fatal outcomes [1]. Both viruses, (i.e., influenza and the novel coronavirus) depend on a viral RNA polymerase and use surface proteins to infect the host [2]. The potential interaction between the influenza vaccine and SARS-CoV-2 infection has attracted the attention of some researchers. Moreover, authors from the Netherlands suggest that a quadrivalent inactivated influenza vaccine can induce trained humoral immunity in an organism or other mechanisms through which an enhanced antiviral state is acquired after vaccination [3]. Some current published data suggest that flu vaccinations can augment immunity against other viral infections, such as SARS-CoV-2 [4]. Humoral immune responses to SARS-CoV-2 are mediated by antibodies that are directed to viral surface proteins, mainly the spike glycoprotein and the nucleocapsid protein, and such antibodies neutralize the viral infection of human cells [5]. Annual influenza vaccination is recommended to protect against infection with seasonal influenza viruses [6]. Discussion about the potential benefits or risks of influenza vaccination on the risk of COVID-19 persists, although there is no clear scientific explanation for a possible effect of influenza vaccination on the risk of SARS-CoV-2 infection [7-11]. The results of a cohort study among Spanish healthcare workers suggested that influenza vaccinations do not significantly modify the risk of SARSCoV-2 infection. The adjusted odds ratio was OR $=1.07 ; 95 \% \mathrm{CI}, 0.92-1.24$ and $\mathrm{OR}=0.86$; $95 \%$ CI, 0.68-1.08, respectively, in the whole group and in symptomatic patients [12]. However, in the EPICOVID19 questionnaire study conducted in Italy, influenza vaccinations were associated with a decreased probability of a SARS-CoV-2-positive test in the younger 
participants ( $\mathrm{OR}=0.85,95 \% \mathrm{CI}, 0.74-0.98)$ [13]. Other authors have posited the minimum number of influenza vaccinations needed to obtain herd immunity [14].

The objective of the study is to compare the occurrence of positive SARS-CoV-2 IgG and IgM tests in subjects with and without recent (last year) seasonal influenza vaccination. The hypothesis assumes that the frequency of positive IgG and IgM tests is lower in people vaccinated against seasonal influenza than in nonvaccinated.

\section{Materials and Methods}

The study was performed as a cross-sectional seroepidemiological survey. It was located in three Silesian Voivodeship towns: Katowice, Gliwice, and Sosnowiec, with an estimated summary population of 694,000 inhabitants, which represents about $33 \%$ of the source populations. The study protocol was described at the ClinicalTrials.gov PRS system website, and the project was given a registration number: ClinicalTrials.gov Identifier: NCT04627623 [15]. Having obtained names and postal addresses, we sent invitations to 6000 people. The sample size calculation was performed for obtaining the required number of participants (Supplementary S1). The first invitation letter was sent in August and September, and in October, all selected participants received a second invitation as a reminder. Only 1167 people (19.5\% of those invited) expressed written consent to participate in the study. Ultimately, we introduced a supplementary recruitment in which we obtained 4312 spontaneous applicated residents of the selected cities $(74.1 \%$ of the 5815 people willing to be tested for antibodies). The final group included 5479 residents (91.3\% of the assumed number of people); age and sex distribution of the study group did not differ from the distribution in the general population of the Silesian Voivodeship [16] (Supplementary Figure S1).

All participants underwent questionnaires and laboratory examinations in local laboratories affiliated within the network "Diagnostyka". The questionnaire included demographical questions, as well as questions on COVID-19 diagnosis, symptoms suggestive of a viral infection in the period preceding IgG and IgM antibodies measurement, and questions on the history of flu vaccination in the last year (yes/no/I do not know). The questionnaire was adopted and based on WHO protocol [17] and presented in Supplementary S2. At each local laboratory, blood samples were tested using a semiquantitative commercial test kit ELISA (EuroImmun Polska Sp z o.o., Wrocław, Poland). Antibodies IgG and IgM were measured against the S1 proteins of SARS-CoV-2 in serum, and the results were expressed as ratios (test/control extinction), according to the following scale: ratio $<0.8=$ negative result, ratio $0.8-1.09=$ questionable result, and ratio $>1.09=$ positive result (the specificity and maximum sensitivity of the IgG test was $99 \%$ and $88 \%$, respectively). Ethical approval for this study was obtained from Ethics Committee of Medical University of Silesia in Katowice (no PCN/0022/KB1/61/20), with the date of approval 14/07/2020.

Statistical analyses were performed using the procedures of the $\mathrm{R}$ statistical package v.3.6.2 (2019, The R Foundation for Statistical Computing, GNU General Public License; The Comprehensive R Archive Network). The distribution of quantitative variables was presented as the mean values and their standard deviations, and the categorical values (such as the prevalence of positive IgG and IgM tests) were presented as absolute (n) and relative frequencies (\%). Between-group differences in the distribution of qualitative variables were tested by the chi-square (or Fisher's) test. Moreover, to assess the relationship between the positive anti-SARS-CoV-2 result and declared seasonal influenza vaccination, the crude odds ratio and $95 \% \mathrm{CI}$ (confidence interval) were used. Adjusted odds ratios were verified using multiple logistic regression in which IgM or IgG results, such as the dependent variable and sex, age, declared diseases, obesity and/or overweight, previous COVID-19 contact or quarantine, and influenza vaccination, were the explanatory variables. We checked the collinearity of the independent variables used in the model, and we did not identify the autocorrelation between them. Finally, a backward stepwise regression was used to assess the relationship between the positive results of the antibodies test and 
the particular classification variables. In the interpretation of the results, $p$-values below 0.05 were considered statistically significant.

\section{Results}

In the group of 5479 subjects, 1253 (22.9\%) had a positive anti-SARS-CoV-2 IgG test, and $400(7.3 \%)$ had a positive anti-SARS-CoV-2 IgM test. Vaccinations against influenza in the last year were reported in $903(16.5 \%)$ of the study participants. Table 1 shows sex, age, COVID-19-related history, and occurrence of chronic diseases according to the influenza vaccination status.

Table 1. Sex, age, COVID-19 related history, and the occurrence of chronic diseases, according to the influenza vaccination status (relative values in the parentheses).

\begin{tabular}{|c|c|c|c|c|c|}
\hline Influenza Vaccination in & t Year & Total 5479 & No $4576(100)$ * & Yes $903(100)$ * & $p$-Value \\
\hline \multirow[b]{2}{*}{ Sex } & Male & 2287 & 1895 (41.4) & $392(43.4)$ & \multirow[b]{2}{*}{$0.2^{1}$} \\
\hline & Female & 3192 & $2681(58.6)$ & $511(56.6)$ & \\
\hline \multicolumn{2}{|l|}{ Age (years) } & $43.9 \pm 16.8$ & $43.1 \pm 16.6$ & $47.7 \pm 17.6$ & $p<0.0001^{2}$ \\
\hline \multirow{2}{*}{$\begin{array}{l}\text { Body Mass Index Overweight } \\
\text { and obese }\end{array}$} & No & 2382 & $2001(47.4)$ & $381(46.0)$ & \multirow[b]{2}{*}{$0.4^{1}$} \\
\hline & Yes & 2669 & $2221(52.6)$ & $448(54.0)$ & \\
\hline \multirow{2}{*}{$\begin{array}{c}\text { Contact with COVID-19 or } \\
\text { quarantine }\end{array}$} & No & 3618 & $3035(66.3)$ & $583(64.6)$ & \multirow[b]{2}{*}{$0.3^{1}$} \\
\hline & Declared & 1861 & $154133.7)$ & $320(35.4)$ & \\
\hline \multirow{2}{*}{ Hypertension } & No & 4138 & $3510(76.7)$ & $628(69.5)$ & \multirow{2}{*}{$p<0.0001^{1}$} \\
\hline & Declared & 1341 & $1066(23.3)$ & $275(30.5)$ & \\
\hline \multirow{2}{*}{ Diabetes } & No & 5126 & $4294(93.8)$ & $832(92.1)$ & \multirow[b]{2}{*}{$0.06^{1}$} \\
\hline & Declared & 353 & $282(6.2)$ & $71(7.9)$ & \\
\hline \multirow{2}{*}{ Chronic allergy } & No & 4851 & $4071(89.0)$ & $780(86.4)$ & \multirow{2}{*}{$0.03^{1}$} \\
\hline & Declared & 628 & $505(11.0)$ & $123(13.6)$ & \\
\hline \multirow[b]{2}{*}{ Autoimmune diseases } & No & 5112 & $4266(93.2)$ & $846(93.7)$ & \multirow[b]{2}{*}{$0.6^{1}$} \\
\hline & Declared & 367 & $310(6.8)$ & $57(6.3)$ & \\
\hline \multirow{2}{*}{$\begin{array}{l}\text { Comorbidity (two or more } \\
\text { coexisting diseases) }\end{array}$} & No & 4714 & $3960(86.5)$ & 754 (83.5) & \multirow{2}{*}{$0.02^{1}$} \\
\hline & Declared & 765 & $616(13.5)$ & 149 (16.5) & \\
\hline
\end{tabular}

Legend: ${ }^{1}-p$-results of the $\chi 2$ test for the categorical values, ${ }^{2}-p$-results of the Mann-Whitney $U$ test for quantitative values, and ${ }^{*}$-analysis performed excluding the missing values.

The distribution of sex was similar in both groups $(p=0.2)$. The groups that were compared also showed similarities in terms of the frequency of obesity / overweight $(p=0.4)$, COVID-19-related history $(p=0.3)$, the occurrence of diabetes $(p=0.06)$, and autoimmune diseases $(p=0.6)$. Influenza vaccinated subjects were statistically significantly older $(p<0.0001)$ and more frequently declared the occurrence of hypertension $(p<0.0001)$, chronic allergies $(p=0.03)$, and comorbidities $(p=0.02)$.

The compared groups differed in terms of the seropositivity status (Table 2). The positive SARS-CoV-2 IgG test was statistically significant $(p<0.0001)$ more frequently in nonvaccinated than in vaccinated subjects ( $22.0 \%$ and $15.6 \%$, respectively). The occurrence of positive SARS-CoV-2 IgM tests was similar in both groups (vaccinated subjects: $4.5 \%$ and nonvaccinated subjects: $5.1 \% ; p=0.7$ ). In the subgroups defined by sex or age, there was a similar association between the influenza vaccination status and positive SARS-CoV2 antibody tests (Table 2). Moreover, the frequency of questionable results (Ques) of the IgG antibodies test concerned 103 subjects $(1.9 \%)$ and, in the case of IgM antibodies, respectively, 125 subjects (2.3\%). In a further analysis connected with the categories "questionable" and "negative", the results of the test were grouped into two categories: positive results or nonpositive results (Table 3). 
Table 2. Association between the SARS-CoV-2 serological status and influenza vaccinations in all subjects and their specific subgroups defined by sex and age and COVID-19-related history.

\begin{tabular}{|c|c|c|c|c|c|c|c|c|}
\hline \multirow{3}{*}{$\begin{array}{l}\text { Influenza Vaccination } \\
\text { in Last Year }\end{array}$} & \multicolumn{8}{|c|}{ Total Study Group $(\mathrm{N}=5479)$} \\
\hline & \multicolumn{4}{|c|}{$\begin{array}{c}\text { Anti-SARS-CoV-2 Antibodies IgG } \\
N(\%)\end{array}$} & \multicolumn{4}{|c|}{$\begin{array}{c}\text { Anti-SARS-CoV-2 Antibodies IgM } \\
N(\%)\end{array}$} \\
\hline & Neg & Ques & Pos & $p$ Value & Neg & Ques & Pos & $p$ Value \\
\hline \multirow{3}{*}{$\begin{array}{c}\text { Yes } 903(100) \\
\text { No or I do not know } 4576(100)\end{array}$} & $753(83.4)$ & $9(1)$ & $141(15.6)$ & & $842(93.2)$ & $20(2.2)$ & $41(4.5)$ & \\
\hline & $3473(75.9)$ & $94(2.1)$ & $1009(22.0)$ & $<0.0001$ & $4237(92.6)$ & $105(2.3)$ & $234(5.1)$ & 0.7 \\
\hline & \multicolumn{8}{|c|}{ Male subjects $(N=2287)$} \\
\hline \multirow{3}{*}{$\begin{array}{c}\text { Yes } 392(100) \\
\text { No or I do not know } 1895(100)\end{array}$} & $328(83.7)$ & $1(0.3)$ & $63(16.0)$ & & $369(94.1)$ & $5(1.3)$ & $18(4.6)$ & \\
\hline & $1449(76.4)$ & $39(2.1)$ & 407 (21.5) & 0.0007 & $1774(93.6)$ & $38(2.0)$ & $83(4.4)$ & 0.6 \\
\hline & \multicolumn{8}{|c|}{ Female subjects $(N=3192)$} \\
\hline \multirow{3}{*}{$\begin{array}{c}\text { Yes } 511(100) \\
\text { No or I do not know } 2681(100)\end{array}$} & $425(83.2)$ & $8(1.6)$ & $78(15.2)$ & & $473(92.5)$ & $15(2.9)$ & $23(4.5)$ & \\
\hline & $2024(75.5)$ & $55(2.0)$ & $602(22.5)$ & 0.0008 & $2463(91.9)$ & $67(2.5)$ & $151(5.6)$ & 0.5 \\
\hline & \multicolumn{8}{|c|}{ Subjects aged below 65 years $(N=4741)$} \\
\hline \multirow{3}{*}{$\begin{array}{c}\text { Yes } 721(100) \\
\text { No or I do not know } 4020(100)\end{array}$} & $588(81.6)$ & $9(1.2)$ & $124(17.2)$ & \multirow{2}{*}{0.0006} & $674(93.5)$ & $15(2.1)$ & $32(4.4)$ & \multirow{2}{*}{0.9} \\
\hline & $3016(75)$ & $89(2.2)$ & $915(22.8)$ & & $3739(93)$ & $89(2.2)$ & $192(4.8)$ & \\
\hline & \multicolumn{8}{|c|}{ Subjects aged $65+$ years $(N=681)$} \\
\hline Yes $171(100)$ & $155(90.6)$ & $0(0)$ & $16(9.4)$ & \multirow[b]{2}{*}{0.05} & $159(93)$ & $5(2.9)$ & $7(4.1)$ & \multirow[b]{2}{*}{0.2} \\
\hline No or I do not know 510 (100) & $425(83.3)$ & $3(0.6)$ & $82(16.1)$ & & $458(89.8)$ & $13(2.5)$ & $39(7.7)$ & \\
\hline \multicolumn{9}{|c|}{ Subjects with contact with COVID-19 or quarantine $(N=3618)$} \\
\hline Yes (100) & $510(87.5)$ & $4(0.7)$ & $69(11.8)$ & \multirow[b]{2}{*}{0.004} & $552(94.7)$ & $12(2.1)$ & $19(3.2)$ & \multirow{2}{*}{0.5} \\
\hline No or I do not know (100) & $2495(82.2)$ & $57(1.9)$ & $483(15.9)$ & & $2862(94.3)$ & $50(1.6)$ & $123(4.1)$ & \\
\hline \multicolumn{9}{|c|}{ Subject without contact with COVID-19 or quarantine $(N=1861)$} \\
\hline Yes $(100)$ & $243(75.9)$ & $5(1.6)$ & $72(22.5)$ & $p<$ & $290(90.6)$ & $8(2.5)$ & $22(6.9)$ & \multirow{2}{*}{0.6} \\
\hline No or I do not know (100) & $978(63.5)$ & $37(2.4)$ & $526(34.1)$ & 0.0001 & 1375 (89.2) & $55(3.6)$ & $111(7.2)$ & \\
\hline
\end{tabular}

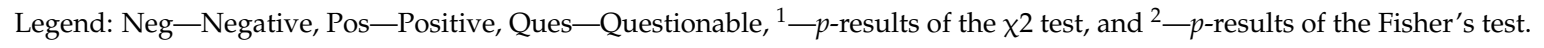

Table 3. Crude odds ratio and its $95 \%$ confidence interval (CI) for the relationship between seasonal influenza vaccination ("Yes" vs. "No or I Do Not Know") and the results of the SARS-CoV-2 IgG and IgM tests.

\section{Classification Variable (Stratum)}

Total population
Male
Female
Younger (<65 years)
Older (65+ years)
Overweight and obese

Declared previous contact with

COVID-19 or quarantine

Declared hypertension

Declared diabetes

Declared chronic allergy

Declared autoimmune diseases

Declared comorbidity (two or more coexisting diseases)
Odds Ratio (95\%CI)

IgG Antibodies (Positive vs. Nonpositive ${ }^{1}$ )

IgM Antibodies (Positive vs. Nonpositive ${ }^{1}$ )
$0.65(0.54-0.79)$
$0.70(0.52-0.93)$
$0.62(0.48-0.80)$
$0.70(0.57-0.86)$
$0.54(0.29-0.93)$
$0.73(0.56-0.94)$
$0.56(0.42-0.74)$
$0.63(0.43-0.91)$
$0.34(0.12-0.82)$
$0.47(0.26-0.82)$
$0.19(0.04-0.53)$
$0.54(0.31-0.90)$

Legend: ${ }^{1}$-Nonpositive anti-SARS-CoV-2 test (in presented analysis) includes negative and, also, questionable results.

Table 3 shows the estimated crude odds ratios, revealing that the seasonal influenza vaccination in the year preceding the study had a protective effect on the occurrence of positive IgG test results in the total group, as well as in the subgroups defined by sex, age, a history of chronic diseases, and previous COVID-19 contact or quarantine. 
Influenza vaccinated

Age [years]

COVID-19 contact

Overweight and obese
Figures 1 and 2 present the results of the backward stepwise regression used to assess the relationship between the positive results of the $\operatorname{IgG}$ or IgM test and particular classification variables. In the case of IgG antibodies, the risk of a positive test was more than twice as high among subjects with declared previous COVID-19 contact or quarantine $(\mathrm{OR}=2.54 ; 2.21-2.93)$. Statistically significant relationships were also confirmed in obese or overweight people $(\mathrm{OR}=1.25 ; 1.08-1.45)$. On the other hand, seasonal influenza vaccinations remain an independent factor protecting against positive $\operatorname{IgG}$ tests $(\mathrm{OR}=0.68$; $0.55-0.83$ ). Interestingly, older age is protective of the assessed relationship (OR $=0.993$; $0.988-0.997)$. In the case of IgM, a positive antibodies test occurred significantly often in females ( $\mathrm{OR}=1.31 ; 1.003-1.732)$, in older age ( $\mathrm{OR}=1.02 ; 1.01-1.03)$, in overweight or obese people (OR $=1.46 ; 1.11-1.95)$, and in people with previous COVID-19 contact or quarantine $(\mathrm{OR}=1.92,1.48-2.49)$.

0.3

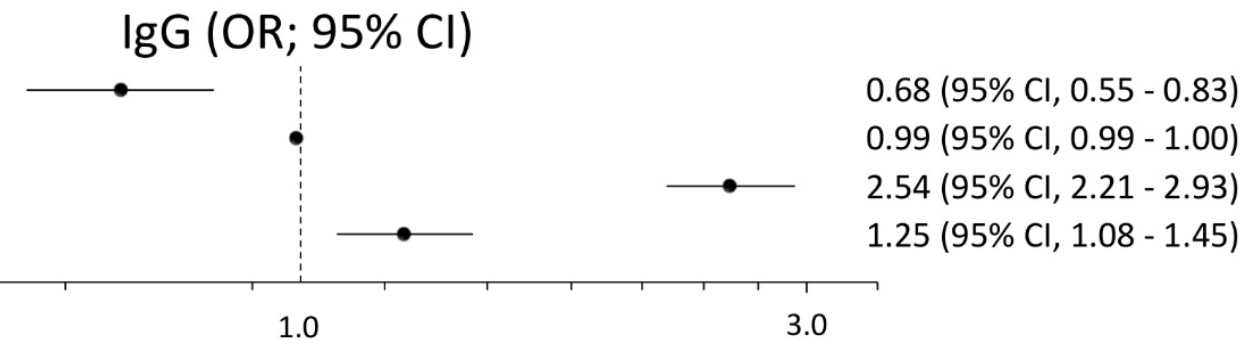

Figure 1. Results of the multivariable analysis (adjusted odds ratio and its $95 \%$ confidence interval) for the relationship between the positive results of the IgG test and particular classification variables.

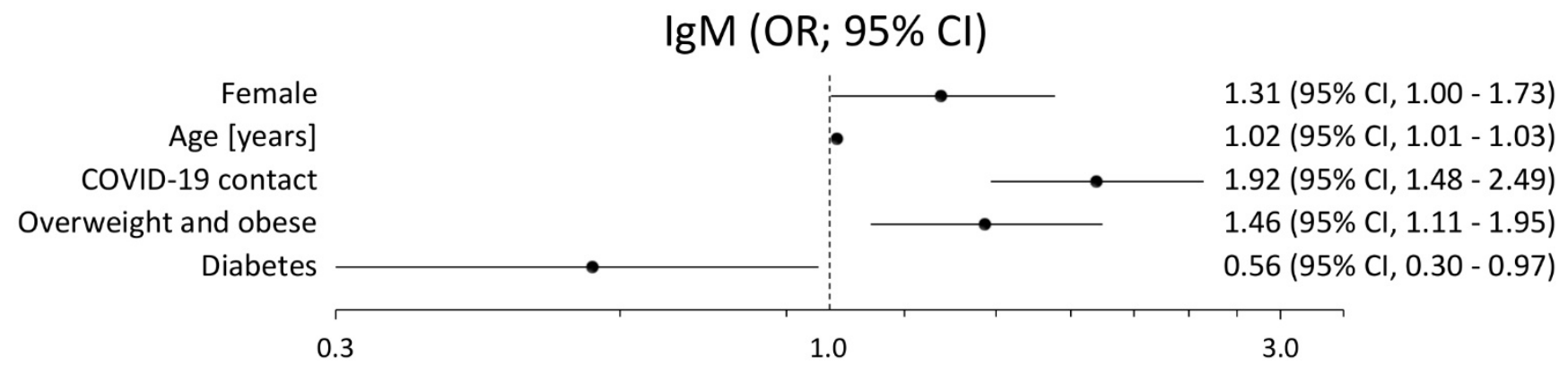

Figure 2. Results of the multivariable analysis (adjusted odds ratio and its 95\% confidence interval) for the relationship between the positive results of the IgM test and particular classification variables.

\section{Discussion}

The SARS-CoV-2 virus and influenza virus share transmission routes, infections have common clinical manifestations, and both infections may coexist. A Chinese study performed at the beginning of the pandemic showed that $57 \%$ out of 307 SARS-CoV2 infected patients were positive for influenza viruses [18]. However, several other studies did not confirm frequent coinfections $[19,20]$.

A similar etiopathogenic background of both diseases provokes important practical questions concerning coexisting influenza and SARS-CoV-2 infections. From an epidemiological point of view, the answers to such questions are important because of the overlap of both epidemics in a real-life setting [21]. One question addresses the impact of coexisting influenza on the severity of SARS-CoV-2 infection. A large study performed in England showed that coinfections increase the risk of COVID-19 death by 2.4 [22].

Another question is whether existing influenza infections increase the risk of SARS$\mathrm{CoV}-2$ infection. Although there is no convincing evidence from human studies, the findings of recently published cellular and animal experiments show that infection with the influenza virus enhances SARS-CoV-2 infectivity [23]. The authors suggest that influenza 
vaccination should be recommended to people with a high risk of SARS-CoV-2 infection. The results of our study showed in a population setting that the occurrence of anti-SARS-CoV-2 IgG antibodies was statistically significantly less frequent in people who had undergone vaccination for seasonal influenza ( $15.6 \%$ vs. $22.0 \%)$. No similar effect was found in IgM antibodies. The protective effect of vaccination (OR $=0.68 ; 95 \% \mathrm{CI} 0.55-0.83$ ) was seen after the adjustment for age, sex, history of COVID-19 contacts, and chronic health conditions.

Our findings are in line with the results of the ecological study in Italy that showed an inverse association between influenza vaccination coverage and SARS-CoV-2 seroprevalence [7]. Other studies have reported the same directionality of the relationship between influenza vaccination prevalence and COVID-19 hospitalizations and mortality [24]. The ecological study in the USA reported a protective effect of the influenza vaccine on COVID-19 mortality in the elderly [9]. The results showed that each $10 \%$ increase in vaccination coverage was associated with a $28 \%$ decrease in the COVID-19 death rate. Another American study showed that SARS-CoV-2-positive patients appear to be less symptomatic and have a less severe course of COVID-19 if they already received a seasonal influenza vaccine in the current flu season and were vaccinated for pneumococcal vaccines [25]. However, in the authors' opinion, such an effect could result from the more restrictive lifestyle of vaccinated people during the COVID-19 pandemic.

An important association of SARS-CoV-2 seropositivity and vaccination against influenza was observed in a large study (over 27,000 patients) performed in Michigan (USA). Compared with nonvaccinated patients, the vaccinated group showed a less frequent occurrence of positive tests (OR $=0.82 ; 95 \%$ CI 0.73-0.92), a lower rate of hospitalizations, and a shorter length of in-hospital stay, as well as a decreased need for mechanical ventilation [26].

There are several potential explanations for the protective effect of influenza vaccination against COVID-19. Firstly, it could reflect a selection mechanism. People who observe health-driven precautions might be more likely to accept influenza vaccinations, and at the same time, they might be more likely to effectively follow public health recommendations during the pandemic. Other mechanisms might be related to vaccination-induced changes in the nonspecific immune response. Moreover, the results of the recent studies showed that people vaccinated against influenza have a higher willingness to get vaccinated against SARS-CoV-2, which is a very positive phenomenon in public health $[27,28]$.

The $\mathrm{T}$ cell-mediated response is believed to play an important role. It cannot be excluded that vaccination against influenza induces a weaker, virus-specific CD8 T-cell immune response compared to the case of natural infection. As a result, $\mathrm{T}$ cells develop more diversity, which increases the potential for protection against other infections. Unvaccinated individuals are more likely to have a higher proportion of influenza-specific resident memory $\mathrm{T}$ cells in the lungs, which are highly productive of inflammatory cytokines. This might be associated with the exaggerated inflammatory response and severe Acute Respiratory Distress Syndrome observed in some COVID-19 patients [9]. The protocols used in our study do not allow for the interpretation of the underlying mechanisms of the protective effect of influenza vaccination against SARS-CoV-2 infection.

Other statistically significant correlations of IgG seropositivity found in our study were age, contact with COVID-19 patients, and overweight/obesity. For IgM seropositivity, the additional statistically significant correlation was diabetes. The effect of age in association with the influenza vaccination is also known from mortality studies. The study in Brazil showed that, in nonvaccinated patients, the COVID-19 mortality was $14 \%$ in children and $84 \%$ in the elderly, whereas, in vaccinated patients, the COVID-19 mortality was much lower [29]. Moreover, obesity and diabetes were statistically significant risk factors for COVID-19-related mortality in this study. From an epidemiological point of view, it is important that the immune response to SARS-CoV-2 infection is heterogeneous and varies between individuals based on age, environment, and underlying health conditions [16,29-31]. The individual profile of the immune response is pertinent in shaping the 
risk of infection. Unlike studies reporting on the association between influenza vaccination and COVID-19 morbidity and mortality, our study focused on the serological manifestation of SARS-CoV-2 infection in the population setting. We assessed the coronavirus infection status using the measurement of anti-SARS-CoV-2 IgG seropositivity. Moreover, the study was performed using individual data obtained via a cross-sectional design. However, there were some pertinent study limitations. First, the data on the history of vaccination against influenza were collected using a questionnaire, and their true reliability remains unknown, as in other questionnaire-based epidemiological studies. Moreover, we did not collect information on the exact date or type of influenza vaccination, although seasonal influenza vaccinations offered in the second half of 2020 were inactivated quadrivalent vaccines. [11]. Due to these limitations, we recommend further studies needed to confirm a detailed association between the type and date of influenza vaccination and positive results of antiSARS-CoV-2. Furthermore, recruitment is a possible limitation of this study. For example, the first group was randomly selected, and the second included a supplementary sample in which there was more female participants, as well as people who declared previous contact with COVID-19 and seasonal influenza-vaccinated people (12.2\% vs. $17.6 \%$, respectively), as well as people without declared chronic diseases. Both groups had similar profiles concerning age. We plan to publish those observations soon in a methodological article.

\section{Conclusions}

In conclusion, our findings suggest that a reported history of vaccination against seasonal influenza was negatively associated with SARS-CoV-2 infection, as evidenced by $\mathrm{IgG}$, but not IgM, antibodies in the spike protein $(\mathrm{OR}=0.68 ; 0.55-0.83)$.

Supplementary Materials: The following are available online at https:/ / www.mdpi.com/article/10 .3390 /vaccines 9050415/s1, Supplementary S1: Sample size calculation; Figure S1: Age structure of Silesian population and compared groups (random and supplementary sample); Supplementary S2: Seroepidemiological questionnaire for COVID 19 infections.

Author Contributions: Conceptualization, M.K.; methodology, M.K., J.E.Z. and G.B.; formal analysis, E.N.; investigation, K.B. and A.K.-P.; writing-review and editing, M.K. and J.E.Z.; visualization, M.K., E.N. and J.E.Z.; supervision, J.E.Z.; project administration, J.E.Z.; and funding acquisition, J.E.Z. All authors have read and agreed to the published version of the manuscript.

Funding: The results of this study were a consequence of a project titled: Prevalence and Risk Factors of COVID-19 in the Upper Silesian Agglomeration (EpiSARS2), supported by the Medical Research Agency in Poland (2020/ABM/COVID19/0044).

Institutional Review Board Statement: The study was conducted according to the guidelines of the Declaration of Helsinki and approved by the Institutional Review Ethics Committee of the Medical University of Silesia (protocol code PCN/0022/KB1/61/20 approved at 14 July 2020).

Informed Consent Statement: Informed consent was obtained from all subjects involved in the study.

Data Availability Statement: The data is available on the request in the Department of Epidemiology, Medical University of Silesia in Katowice. The request should be formulated and send to epikat@sum.edu.pl.

Acknowledgments: The authors would like to thank all the medical students who took part in the study. In addition, we would like to express our gratitude to F.D. for improvements to the English language of this manuscript.

Conflicts of Interest: The authors declare no conflict of interest.

\section{References}

1. Maltezou, H.C.; Theodoridou, K.; Poland, G. Influenza immunization and COVID-19. Vaccine 2020, 38, 6078-6079. [CrossRef] [PubMed]

2. Manzanares-Meza, L.D.; Medina-Contreras, O. SARS-CoV-2 and influenza: A comparative overview and treatment implications. Bol. Med. Hosp. Infant. Mex. 2020, 77, 262-273. [CrossRef] [PubMed] 
3. Debisarun, P.A.; Struycken, P.; Domínguez-Andrés, J.; Moorlag, S.J.C.F.M.; Taks, E.; Gössling, K.L.; Ostermann, P.N.; Müller, L.; Schaal, H.; ten Oever, J.; et al. The effect of influenza vaccination on trained immunity: Impact on COVID-19. BMJ Yale 2020. [CrossRef]

4. Salem, M.L.; El-Hennawy, D. The possible beneficial adjuvant effect of influenza vaccine to minimize the severity of COVID-19. Med. Hypotheses 2020, 140, 10975. [CrossRef] [PubMed]

5. Poland, G.A.; Ovsyannikova, I.G.; Kennedy, R.B. SARS-CoV-2 immunity: Review and applications to phase 3 vaccine candidates. Lancet 2020, 396, 1595-1606. [CrossRef]

6. Altenburg, A.F.; Kreijtz, J.H.C.M.; de Vries, R.D.; Song, F.; Fux, R.; Rimmelzwaan, G.F.; Sutter, G.; Asisa, V. Modified Vaccinia Virus Ankara (MVA) as Production Platform for Vaccines against Influenza and Other Viral Respiratory Diseases. Viruses 2014, 6, 2735-2761. [CrossRef]

7. Amato, M.; Werba, J.P.; Frigerio, B.; Coggi, D.; Sansaro, D.; Ravani, A.; Ferrante, P.; Veglia, F.; Tremoli, E.; Baldassarre, D. Relationship between Influenza Vaccination Coverage Rate and COVID-19 Outbreak: An Italian Ecological Study. Vaccines 2020, 8, 535. [CrossRef] [PubMed]

8. Marín-Hernández, D.; Schwartz, R.E.; Nixon, D.F. Epidemiological evidence for association between higher influenza vaccine uptake in the elderly and lower COVID-19 deaths in Italy. J. Med. Virol. 2020, 1-2. [CrossRef]

9. Zanettini, C.; Omar, M.; Dinalankara, W.; Imada, E.L.; Colantuoni, E.; Parmigiani, G.; Marchionni, L. Influenza Vaccination and COVID19 Mortality in the USA. medRxiv 2020. [CrossRef]

10. Sultana, J.; Mazzaglia, G.; Luxi, N.; Cancellieri, A.; Capuano, A.; Ferrajolo, C.; de Waure, C.; Ferlazzo, G.; Trifiró, G. Potential effects of vaccinations on the prevention of COVID-19: Rationale, clinical evidence, risks, and public health considerations. Expert Rev. Vaccines 2020, 19, 919-936. [CrossRef]

11. Del Riccio, M.; Lorini, L.; Bonaccorsi, G.; Paget, J.; Caini, S. The Association between Influenza Vaccination and the Risk of SARS-CoV-2 Infection, Severe Illness, and Death: A Systematic Review of the Literature. Int. J. Environ. Res. Public Health 2020, 17, 7870. [CrossRef]

12. Martínez-Baz, I.; Trobajo-Sanmartín, C.; Arregui, I.; Navascués, A.; Adelantado, M.; Indurain, J.; Fresán, U.; Ezpeleta, C.; Castilla, J. Influenza Vaccination and Risk of SARS-CoV-2 Infection in a Cohort of Health Workers. Vaccines 2020, 15, 611. [CrossRef] [PubMed]

13. Noale, M.; Trevisan, C.; Maggi, S.; Incalzi, R.A.; Pedone, C.; Di Bari, M.; Adorni, F.; Jesuthasan, N.; Sojic, A.; Galli, M.; et al. The Association between Influenza and Pneumococcal Vaccinations and SARS-Cov-2 Infection: Data from the EPICOVID19 WebBased Survey. Vaccines 2020, 8, 471. [CrossRef]

14. Grech, V.; Borg, M. Influenza vaccination in the COVID-19 era. Early Hum. Dev. 2020, 148, 105116. [CrossRef] [PubMed]

15. ClinicalTrials.gov Identifier: NCT04627623. Available online: https:/ / clinicaltrials.gov/ct2/show/NCT04627623 (accessed on 12 November 2020).

16. Zejda, J.E.; Brożek, G.M.; Kowalska, M.; Barański, K.; Kaleta-Pilarska, A.; Nowakowski, A.; Xia, Y.; Buszman, P. Seroprevalence of Anti-SARS-CoV-2 Antibodies in a Random Sample of Inhabitants of the Katowice Region, Poland. Int. J. Environ. Res. Public Health 2021, 18, 3188. [CrossRef] [PubMed]

17. WHO. Population-Based Age-Stratified Seroepidemiological Investigation Protocol for COVID-19 Virus Infection. March 2020. Available online: https:/ /apps.who.int/iris/handle/10665/331656 (accessed on 20 March 2020).

18. Yue, H.; Zhang, M.; Xing, L.; Wang, K.; Rao, X.; Liu, H.; Tian, J.; Zhou, P.; Deng, Y.; Shang, J. The epidemiology and clinical characteristics of coinfection of SARS-CoV-2 and influenza viruses in patients during COVID-19 outbreak. J. Med. Virol. 2020, 92, 2870-2873. [CrossRef]

19. Richarson, S.; Hirsch, J.S.; Narasimbam, N. Presenting characteristics, comorbidities and outcomes among 5700 patients hospitalized with COVID-19 in the New York City are. JAMA 2020, 323, 2052-2059. [CrossRef]

20. Kim, D.; Quinn, J.; Pinsky, B.; Shah, N.H.; Brown, I. Rates of co-infection between SARS-CoV-2 and other respiratory pathogens. JAMA 2020, 323, 2085-2086. [CrossRef]

21. Belongia, E.; Osterholm, M. COVID-19 and flu, a perfect storm. Science 2020, 368, 1163. [CrossRef]

22. Lacobucci, G. Covid-19: Risk of death more than doubled in people who also has flu, English data show. Br. Med. J. 2020, 370, 3720. [CrossRef]

23. Bai, L.; Zhao, Y.; Dong, J.; Liang, S.; Guo, M.; Liu, X.; Wang, X.; Huang, Z.; Sun, X.; Zhang, Z.; et al. Coinfection with influenza A virus enhances SARS-CoV-2 infectivity. Cell Res. 2021, 1-9. [CrossRef]

24. Reina, J. Influenza vaccination in the time of SARS-CoV-2. Med. Clin. 2021, 156, 17-19. [CrossRef] [PubMed]

25. Patwardhan, A.; Ohler, A. The Flu Vaccination May Have a Protective Effect on the Course of COVID-19 in the Pediatric Population: When Does Severe Acute Respiratory Syndrome Coronavirus 2 (SARS-CoV-2) Meet Influenza? Cureus 2021, 13, 12533. [CrossRef]

26. Colon, A.; Ashur, C.; Washer, L.; Eagle, K.M.; Hofmann Bowman, M.A. Impact of the influenza vaccine on COVID-19 infection rates and severity. Am. J. Infect. Control. 2021, 1-7. [CrossRef]

27. Szmyd, B.; Karuga, F.F.; Bartoszek, A.; Staniecka, K.; Siwecka, N.; Bartoszek, A.; Błaszczyk, M.; Radek, M. Attitude and Behaviors towards SARS-CoV-2 Vaccination among Healthcare Workers: A Cross-Sectional Study from Poland. Vaccines 2021, 9, 218. [CrossRef]

28. Szmyd, B.; Bartoszek, A.; Karuga, F.F.; Staniecka, K.; Błaszczyk, M.; Radek, M. Medical Students and SARS-CoV-2 Vaccination: Attitude and Behaviors. Vaccines 2021, 9, 128. [CrossRef] [PubMed] 
29. Fink, G.; Orlova-Fink, N.; Schindler, T.; Grisi, S.; Ferrer, A.P.; Daubenberger, C.; Brentani, A. Inactivated trivalent influenza vaccine is associated with lower mortality among Covid-19 patients in Brazil. BMJ Evid. Based Med. 2020. [CrossRef]

30. Bajgain, K.T.; Badal, S.; Bajgain, B.B.; Santana, M.J. Prevalence of comorbidities among individuals with COVID-19: A rapid review of current literature. Am. J. Infect. Control. 2021, 49, 238-246. [CrossRef]

31. Davies, N.G.; Klepac, P.; Liu, Y.; Prem, K.; Jit, M.; CMMID COVID-19 Working Group; Eggo, R.M. Age-dependent effects in the transmission and control of COVID-19 epidemics. Nat. Med. 2020, 26, 1205-1211. [CrossRef] 